\title{
On the Relationship between the Foramen Spinosum and the Middle Meningeal Artery in the Dog
}

$\mathrm{By}$

\author{
Hitoshi Okuda, Takao Tokioka and Hideo Furuhara \\ Department of Anatomy, Osaka Dental University, Osaka \\ (Director: Prof. Y. Ohta) \\ (with one text figure and 7 figures in 3 plates) \\ - Received for Publication, February 26, 1974-

\section{Preface}

It has been reported that the usual entrance of the middle meningeal artery into the cranial cavity in the dog is the oval foramen or a small foramen located on its wall. The present authors, however, found a vessel which took other passages through other foramina in the vicinity of the oval foramen, especially a foramen posterolateral to it, when they have studied on the general aspect of the middle meningeal artery of the dog. Accordingly, the present studies will deal with foramina neighboring the oval foramen related to passages of the middle meningeal artery.

\section{Materials and Methods}

This observation has been performed on thirty-six dog skulls and one hundred and forty casts of the carotid system of dogs which were prepared by the acryl injection method (Taniguchi et al. 1952, 1955).

\section{Observations}

1. Findings neighboring the foramen spinosum

In this paper the foramen spinosum is the term applied to a foramen (about $1 \mathrm{~mm}$ in diameter) located in about $0.5 \mathrm{~mm}$ posterior or about $1.5 \mathrm{~mm}$ posterolateral to the oval foramen in the major ala of the basisphenoid bone (Fig. 2). This spinosum is observed in 9 out of 72 sides, bilaterally in four cases, unilaterally in one case of all 36 skulls observed.

In one case of all the skulls, a small foramen (about $1 \mathrm{~mm}$ in diameter) is seen on the anterior wall of the oval foramen, and in one 
different case a small incisura on the same area (Fig. 5).

The foramen spinosum continues cranially for $0.5-1 \mathrm{~mm}$ in the alisphenoid bone, bends cranio-postero-laterally for 4-5 mm (Fig. 3), and finally opens into the cranial cavity through the petrosphenoid suture (Fig. 4). From the opening the canal turns into a groove on the anterior surface of the petrosal region of the temporal bone (Fig. 3) up to the middle meningeal arterial groove on the parietal bone though the groove becomes shallow.

2. The findings on the middle meningeal artery (Fig. 1)

The maxillary artery runs medially between the posterior margin of the medial pterygoid muscle and the lateral pterygoid muscle, and bends anteriorly being adjacent to the posterior side of the mandibular nerve beneath the oval foramen to enter the alar canal through the posterior alar foramen. Just proximal to the entrance, the middle meningeal artery is given off from the superior wall of the maxillary artery distal to the arising of the medial pterygoid muscular branch (Tsuji 1969) in the height of the anterior wall of the oval foramen. The artery runs cranially and passes through the anterior wall of the oval foramen into the cranial cavity (Fig. 1-1).

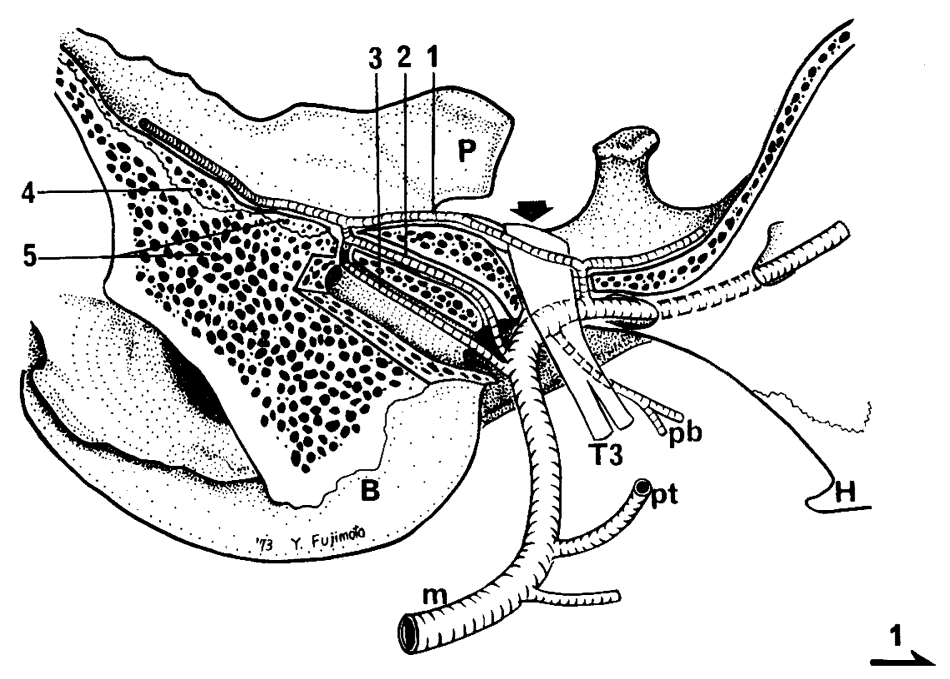

Fig. 1. Schematic illustration of passages of the middle meningeal artery.

1. The artery passing through the oval foramen ( $\downarrow$ ).

2. The artery passing through the foramen spinosum, corresponding to the case (i).

3. The artery passing through the wall of the auditory tube, corresponding to the case (ii).

4. Parietal bone.

5. Temporal bone. 
In cases in which the artery arises proximal to the arising of the medial pterygoid muscular branch, the artery takes courses as follows:

(i) In cases where the foramen spinosum is observed (Fig. 1-2):

The middle meningeal artery arises from the superior or posterosuperior wall of the maxillary artery proximal to the anterior bending mentioned above. The artery runs up to the foramen spinosum passing cranially on the lateral side of the otic ganglion between the $\mathrm{m}$. tensor veli palatini and the auriculotemporal nerve. After entering the foramen, the artery in the osseous substance bends posterolaterally and passes through the petrosphenoid suture into the cranial cavity (Fig. 6), then runs in the groove for the middle meningeal artery of the anterior surface of the petrosal region to follow the parietal bone. The artery also gives off the branch to the $\mathrm{m}$. tensor tympani from its medial wall before entering the spinosum, passing through the wall of the auditory tube.

(ii) In cases where the foramen spinosum is not observed (Fig. 1-3): The middle meningeal artery which is similar to (i) in the arising feature, enters the lateral wall of the auditory tube and runs along the lateral side of the $\mathrm{m}$. tensor veli palatini, the minor petrosal nerve and the $n$. tensoris tympani. The artery, after bending cranially at the anterior margin of the $\mathrm{m}$. tensor tympani, passes through the petrosphenoid suture into the cranial cavity (Figs. 7 and 8), then runs in the groove as mentioned above. The artery, just before entering the wall of the auditory tube, also gives off the branch to the $\mathrm{m}$. tensor tympani which runs along with the parent artery for a short distance.

In both (i) and (ii), the maxillary artery gives off the r. anastomoticus from its superior wall just before entering the posterior alar foramen. The ramus passing through the oval foramen divides into two. One anastomoses with the a. anastomotica and the other, lacking sometimes, anastomoses with the middle meningeal artery at the point where the artery just comes into the cranial cavity. In cases where the $r$. anastomoticus is not observed, a small twig arises near the origin of the middle meningeal artery and communicates with the medial pterygoid muscular branch on the external cranial basis. Peripheries of the twig are distributed to the trigeminal ganglion passing through the oval foramen.

\section{Discussion}

Bradley (1927) and Sisson et al. (1953) and Masui (1957) stated that the middle meningeal artery of the dog passed through the oval 
foramen into the cranial cavity. Ellenberger et al. (1891) found a foramen in contact with the oval foramen. Nickel et al. (1960) stated that the foramen spinosum in carnivora and often incisura in the dog were seen lateral to the oval foramen, but they demonstrated the spinosum as a foramen in the illustration of the vicinity of the foramen lacerum. The present authors have considered that the foramen or incisura located on the anterior or lateral wall of the oval foramen was not the so-called foramen spinosum. Miller (1964) designated a foramen or notch on the anterior wall of the oval foramen as the spinosum in the chapter of the angiology of his textbook, but he described the foramen or incisura on the posterolateral wall of the oval foramen as the foramen spinosum in the chapter of the osteology. The opinion of the present observations was that the foramen on the posterolateral wall of the oval foramen described by Miller and others might not be isolated from the oval foramen, but actually from the petrosphenoid suture as the foramen spinosum. Furthermore, such a suture was not formed in the human subject, cattle and pig, but remained unclosed as the foramen lacerum. In the dog, this suture was closed completely, so that the existence of the foramen spinosum might be unstable. Jewell (1952) stated that the middle meningeal artery of the dog (specimen No. 341) passed through the foramen spinosum into the cranial cavity and the maxillary artery gave off a small branch into the alisphenoid canal and anastomosed with the anastomotic artery after passing through the oval foramen. It was very difficult that the spinosum described by Jewell would correspond to any of the spinosa discussed in this paper, but his findings of the anastomotic branch agreed with those of the present paper. Judging from the features of the vessel, the spinosum of Jewell might be identified as the spinosum located on the posterolateral area of the oval foramen.

Whether the middle meningeal artery might take the passage of the foramen spinosum located on the posterolateral area of the oval foramen or the passage of the wall of the auditory tube, the artery passed through the petrosphenoid suture for running in the groove for the artery of the anterior surface of the petrosal region. So far, there has been no description of the groove of this petrosal region concerning to the middle meningeal artery.

\section{Conclusions}

1. The relationship between the foramen spinosum and the middle meningeal artery in the dog. was surveyed using 36 skulls and the acryl corrosion specimens of the arterial system of 140 heads.

2. The small foramen was observed posterolateral to the oval foramen in 9 sides of all skulls observed. This foramen was desig- 
nated as "foramen spinosum" because the foramen might be isolated from the petrosphenoid suture.

3. The middle meningeal artery passed through the anterior wall of the oval foramen when the artery arose distal to the origin of the medial pterygoid muscular branch. But the artery proximal to the origin of this branch passed through the foramen spinosum or the wall of the auditory tube and entered into the cranial cavity. Whichever passage the artery might take, it ran along the arterial groove of the anterior margin of the petrosal region of the temporal bone, then along that of the parietal bone.

The authors wish to express their thanks to their advisor, Dr. Professor Yoshikuni Ohta, for his excellent advice and encouragement during this study, and also to Associate Professor S. Yamauchi, Osaka Pref. University, for his kind offer of showing them the dog skulls preserved in his laboratory.

\section{Literature cited}

1. Bradley, O.Ch. 1927 : Topographical anatomy of the dog. Oliver \& Boyd, London. $178,179$.

2. Ellenberger, W. and H. Baum. 1891: Systematische und topographische Anatomie des Hundes. Paul Parey, Berlin. 28, 29.

3. Jewell, P.A. 1952: Anastomoses between internal and external carotid circulations in the dog. J. Anat., $86: 83-94$.

4. Masui, K. 1957: Comparative anatomy of the domestic animals. Yokendo, Tokyo. $1: 26-48,2: 24$ (in Japanese).

5. Miller, M.H., G.C. Christensen and H.E. Evans 1964: Anatomy of the dog. W. B. Saunders, Phila., 6-48, 150-316, 550-856.

6. Nickel, R., A. Schummer und E. Seiferle 1954: Lehrbuch der Anatomie der Haustiere. Paul Parey, Berlin. Bd. 1: 149.

7. Sisson, S. and J.D. Grossman 1953: Anatomy of the domestic animals. 4th Ed., W.B. Saunders, Phila., 767.

8. Taniguchi, Y., Y. Ohta and S. Tajiri 1952: New improved method for injection. of acrylic resin. Okajimas Fol. anat. jap., $24: 259-267$.

9. Taniguchi, Y., Y. Ohta, S. Tajiri, H. Okano and H. Hanai 1955: Supplement to new improved method for injection of acrylic resin. Okajimas Fol. anat. jap., 27 : 401-406.

10. Tsuji, O. 1969. Stereological Studies on Several Ducts and Vessels by Injection Method of Acrylic Resin. XXIII. Arterial distribution of the medial pterygoid muscle in some mammals. Okajimas Fol. anat. jap., $46: 21-40$. 


\section{Explanation of Figures \\ Key to Abbreviations}

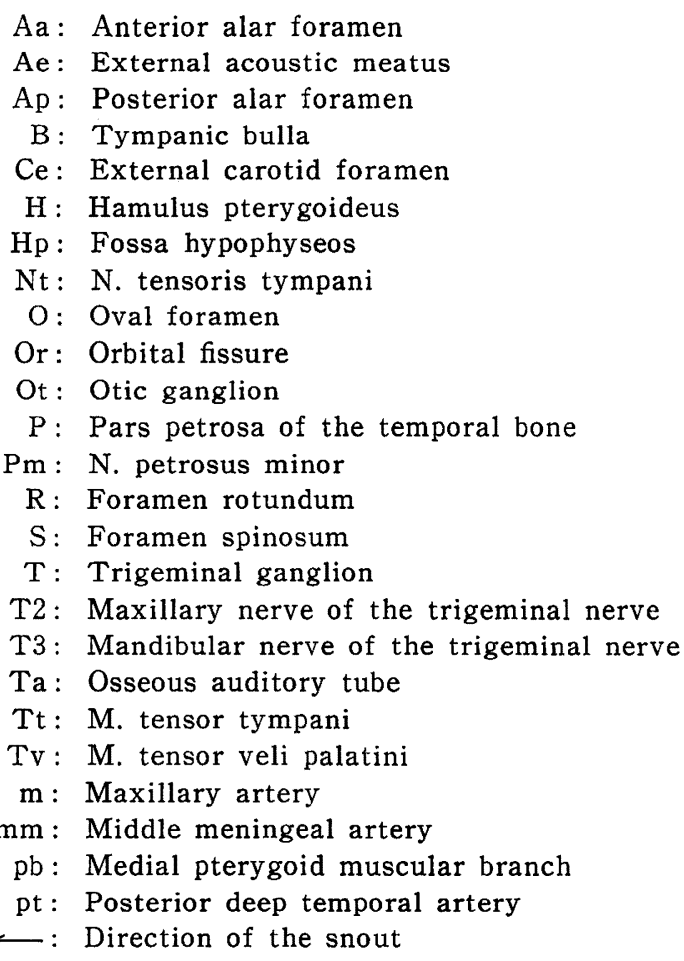

\section{Plate I}

Fig. 2. External cranial basis. The foramen spinosum is seen bilaterally posterolateral to the oval foramen. ca. $\times 3$.

Fig. 3. Internal cranial basis. The internal opening of the foramen spinosum is seen $(\downarrow)$, and continues to the groove on the anterior surface of the petrosal region of the temporal bone $(\uparrow)$. Impressio trigemini $(x)$. ca. $\times 3$.

\section{Plate II}

Fig. 4. Lateral view of the right side of the foramen spinosum. In order to demonstrate the way of the spinosum from its external opening $(\uparrow)$ to its internal opening $(\downarrow)$, bone structures lateral to the spinosum are removed. Posterior clinoid process $(x)$. ca. $x 5$.

Eig. 5. The close-up of the oval foramen and its vicinity, lateral view. An incisura is seen on the anterior wall of the oval foramen $(\uparrow)$ and a foramen in the inset. ca. $\times 3$. 


\section{Plate III}

Fig. 6. The middle meningeal artery passes through the foramen spinosum. Medial view of the right side, bone structures are dissected along the artery. The branch to the $\mathrm{m}$. tensor tympani $(\uparrow)$, the auditory tube $(\leftarrow)$, and the openings of the foramen spinosum (dotted lines), are shown. ca. $\times 6$.

Fig. 7. The middle meningeal artery passes through the lateral wall of the auditory tube $(x \times)$, medial view of the left side, dissected along the auditory tube. The artery is in company with the $\mathrm{m}$. tensor veli palatini, $\mathrm{n}$. petrosus minor $(\downarrow)$, the branch to the $m$. tensor tympani $(\uparrow)$ and $n$. tensoris tympani, membrana tympani $(x)$. ca. $\times 9$.

Fig. 8. Corrosion specimen of figure 7. The branch to the $m$. tensor tympani $(\uparrow)$ arises near the origin of the middle meningeal artery and runs in parallel with it. ca. $\times 9$. 

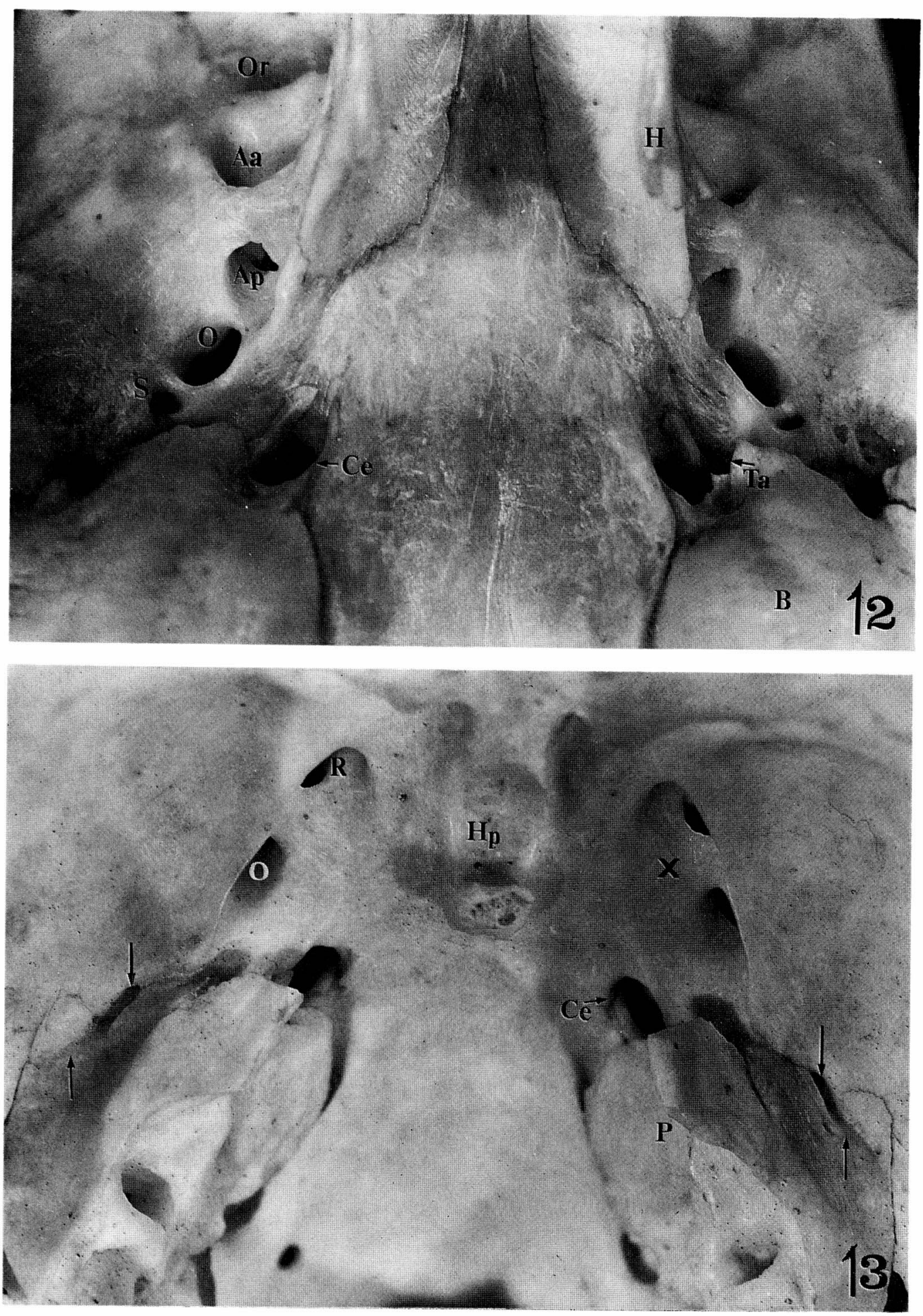

H. Okuda, T. Tokioka \& H. Furuhara 

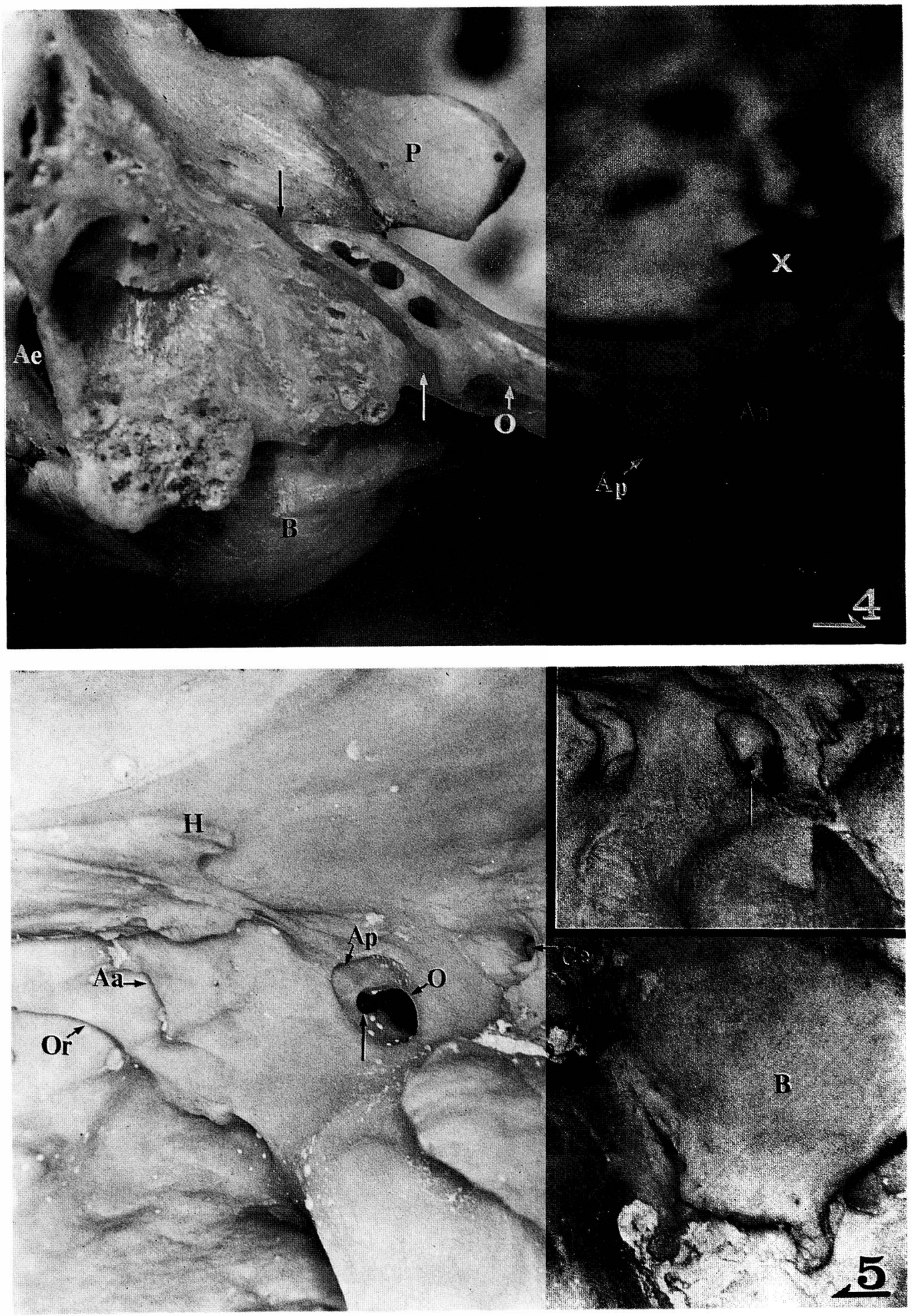

H. Okuda, T. Tokioka \& H. Furuhara 

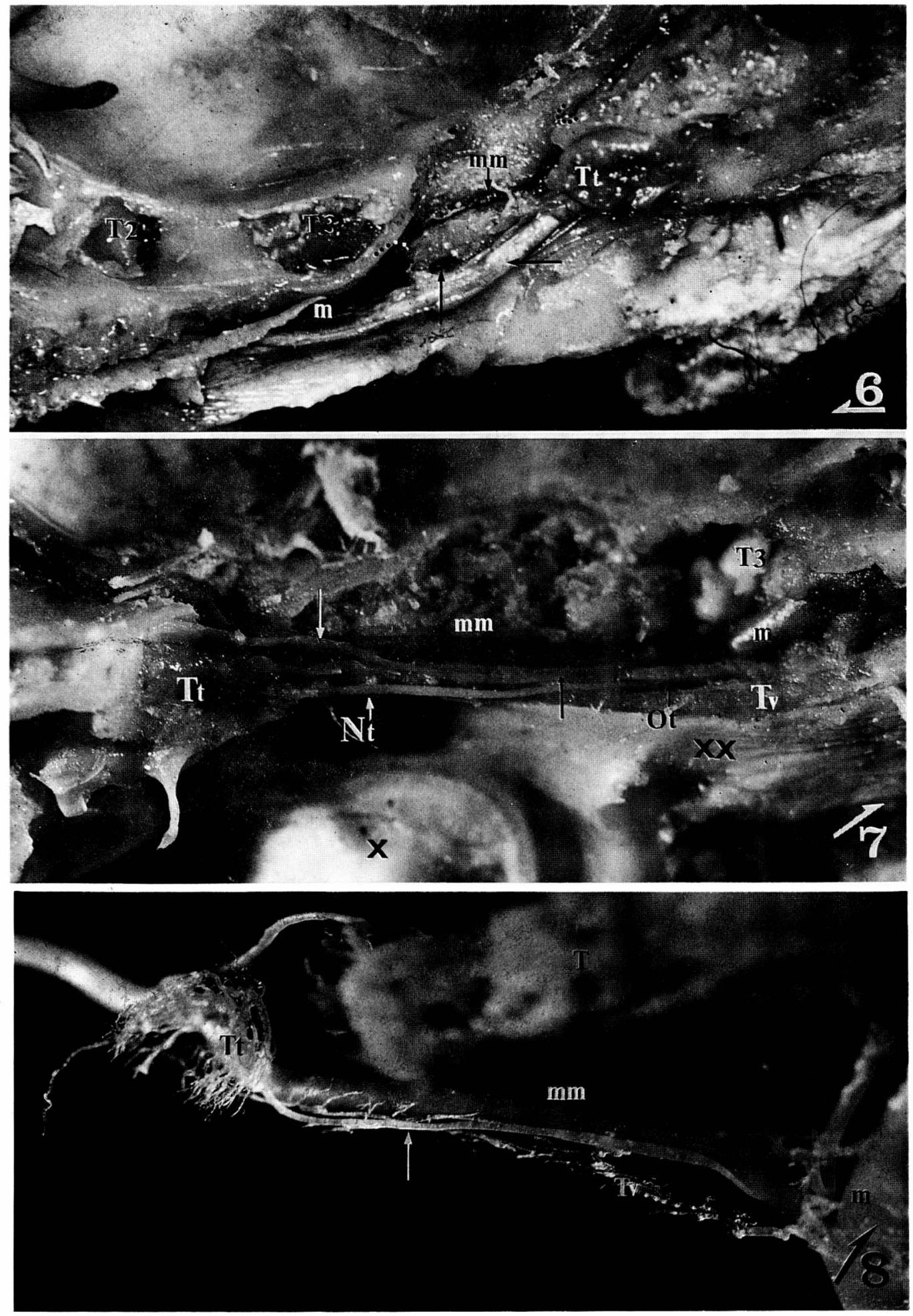

H. Okuda, T. Tokioka \& H. Furuhara 